\title{
Analyses of Composite Sandwich Plates Using Higher Order Computational Models
}

\author{
S. Shantharama Patil
}

\begin{abstract}
In this paper analytical procedure is developed to investigate the static and dynamic characteristics of laminated composite and sandwich plates based on two refined higher order shear displacement models which accounts for adequate distribution of transverse shear strain, normal deformation and non-linear variation of in-plane displacements through the plate thickness. Governing equilibrium equations for stress analysis and equations of motion for free vibration analysis using the different displacement models are obtained using Principle of Minimum Potential Energy. The equations of motion for free vibration analysis are obtained using Hamilton's Principle. The closed form solutions are obtained using Navier's double trigonometric series technique for stress and free vibration analyses. First-order and higher-order shear deformation models are reviewed to bring out their response predictive capabilities. Numerical results are presented for transverse displacement, inplane stresses and natural frequencies using different models for anti-symmetric angle-ply laminated composite and sandwich plates. The accuracy of the solution is ascertained by comparing it with various available results in the literature.
\end{abstract}

Keywords - Computational models, free vibration, sandwich plates, static analysis.

\section{INTRODUCTION}

Composite structures are used in many engineering applications like aerospace, nuclear power plants, automotive, submarines, sport and health instruments as well as in other fields of modern technology. This is because many composite materials exhibit high strength-to-weight and stiffness-toweight ratios, which make them ideally suited for use in weight-sensitive structures. Composite sandwich plates are basically a special form of fibre reinforced plates composed of two thin strong, stiff layers (face sheets) which resist bending bonded to a relatively thicker, less dense layer (core) to resist shear force or also made up of alternative arrangement of thin stiff layers and thick flexible cores. The face sheets are basically prepared from unidirectional fibre reinforced laminated composites. The core is a thick layer of a lower density material made up of foam polymer or honeycomb material. The most important aspect of composite materials in which the reinforcement are fibers is the anisotropy caused by the fiber orientation. The accurate prediction of the response characteristics of laminated structures is a challenging task because of their intrinsic anisotropy, heterogeneity and low ratio of the transverse shear modulus to the in-plane Young's

S. Shantharama Patil is with the Faculty of Architecture, Manipal Institute of Technology, Manipal University, Manipal, Karnataka, 576104 India. modulus. To use the laminated composite and sandwich plates efficiently, it is necessary to develop appropriate analysis theories to predict accurately their structural and dynamical behavior. Many of the developed models for laminated composite plates are based in classical laminate plate theory [1] and first order shear deformation plate theories [2]-[4] are the simplest equivalent single layer theories. It is well known that the classical laminate plate theory is inadequate in modelling laminated composite plates, unless the plate is very thin. This theory underestimates deflections and overestimates natural frequencies and buckling loads. It has been demonstrated that these theories can lead to substantial errors in the prediction of stresses of highly anisotropic and/or moderately thick composite plates [5], [6]. The most important feature of laminated composites and sandwich plates is that these materials are relatively weak in shear due to their low shear modulus compared to that of extensional rigidity. So, the effect of shear deformation is quite significant and it must be suitably taken care of in the analysis of such composite structures to realistically predict their behavior. In order to analyze the composite plate various plate deformation theories developed. The methods of analysing sandwich structures and numerical solutions for the standard problems are well documented in the books by Allen [7] and Plantema [8]. Extensive review of literature for the analysis of sandwich structures is available in the articles by Habib [9], [10], Bert and Francis [11]. Numerous investigators had used various models for the analysis of laminated structures. Moreover, research on laminated plates and shells theories can be found in early review papers by Noor and Burton [12], [13]. Complete reference on the recent research studies on static and dynamic analysis of laminated composite and sandwich plates are available in the articles by Kant and Swaminathan [14], Kant [15], Pandya and Kant [16]-[18] and Kant and Manjunatha [19], Kant and Swaminathan [20]-[22] and Swaminathan and Patil [23]-[25]. In most of the 2D theories developed till date, only transverse shear deformations have been considered, and very few theories consider the effect of both transverse shear and transverse normal deformations. Very limited studies are reported in the literature on the evaluation of the various $2 \mathrm{D}$ higher order theories and about their range of application and the accuracy in predicting the global responses.

\section{THEORIES OF LAMINATED PLATES}

Refined higher order theories can be developed by using displacement fields based on Taylor's series expansions of the 
displacement components $u(x, y, z, t), v(x, y, z, t)$ and $w(x, y, z, t)$ in terms of the thickness coordinate $z$. The following third order displacement field [19] can be written.

Model -1 [19]

$$
\begin{aligned}
& u(x, y, z, t)=u_{o}(x, y, t)+z \theta_{x}(x, y, t)+z^{2} u_{o}^{*}(x, y, t)+z^{3} \theta_{x}^{*}(x, y, t) \\
& (x, y, z, t)=v_{o}(x, y, t)+z \theta_{y}(x, y, t)+z^{2} v_{o}^{*}(x, y, t)+z^{3} \theta_{y}^{*}(x, y, t) \\
& k(x, y, z, t)=w_{o}(x, y, t)+z \theta_{z}(x, y, t)+z^{2} w_{o}^{*}(x, y, t)+z^{3} \theta_{z}^{*}(x, y, t)
\end{aligned}
$$

Deleting the higher order terms corresponding to the displacement $w(x, y, z, t)$ in equation (1), we can obtain an alternative higher order displacement field [18].

Model -2 [18]

$$
\begin{aligned}
& u(x, y, z, t)=u_{o}(x, y, t)+z \theta_{x}(x, y, t)+z^{2} u_{o}^{*}(x, y, t)+z^{3} \theta_{x}^{*}(x, y, t) \\
& v(x, y, z, t)=v_{o}(x, y, t)+z \theta_{y}(x, y, t)+z^{2} v_{o}^{*}(x, y, t)+z^{3} \theta_{y}^{*}(x, y, t) \\
& w(x, y, z, t)=w_{o}(x, y, t)
\end{aligned}
$$

For comparison, the following higher order theories [26], [27] and the first order theory [28] available in the literatures are also considered for the evaluation.

Model -3 [26]

$$
\begin{aligned}
& u(x, y, z, t)=u_{o}(x, y, t)+z\left[\theta_{x}(x, y, t)-\frac{4}{3}\left(\frac{z}{h}\right)^{2}\left\{\theta_{x}(x, y, t)+\frac{\partial w_{o}}{\partial x}\right\}\right] \\
& v(x, y, z, t)=v_{o}(x, y, t)+z\left[\theta_{y}(x, y, t)-\frac{4}{3}\left(\frac{z}{h}\right)^{2}\left\{\theta_{y}(x, y, t)+\frac{\partial w_{o}}{\partial y}\right\}\right] \\
& w(x, y, z, t)=w_{o}(x, y, t)
\end{aligned}
$$

Model-4 [27]

$$
\begin{aligned}
& u(x, y, z, t)=u_{o}(x, y, t)-z \frac{\partial w_{o}^{b}}{\partial x}-\frac{4 z^{3}}{3 h^{2}} \frac{\partial w_{o}^{s}}{\partial x} \\
& v(x, y, z, t)=v_{o}(x, y, t)-z \frac{\partial w_{o}^{b}}{\partial y}-\frac{4 z^{3}}{3 h^{2}} \frac{\partial w_{o}^{s}}{\partial y} \\
& w(x, y, z, t)=w_{o}^{b}(x, y, t)+w_{o}^{s}(x, y, t)
\end{aligned}
$$

Model - 5 [28]

$$
\begin{aligned}
& u(x, y, z, t)=u_{o}(x, y, t)+z \theta_{x}(x, y, t) \\
& v(x, y, z, t)=v_{o}(x, y, t)+z \theta_{y}(x, y, t) \\
& w(x, y, z, t)=w_{o}(x, y, t)
\end{aligned}
$$

Where the terms $u, v$ and $w$ are the displacements of a general point $(x, y, z)$ in the laminate domain in the $x, y$ and $z$ directions respectively. The terms $\boldsymbol{u}_{o}, \boldsymbol{v}_{o}$ are the in-plane displacements $w_{o}, w_{o}^{b}$ and $w_{o}^{s}$ are the transverse displacement, it's bending and shear components respectively of a point $(x, y)$ on the middle plane. The functions $\theta_{x}, \theta_{y}$ are rotations of the normal to the middle plane about $y$ and $x$ axes respectively. The terms $u_{o}^{*}, v_{o}^{*}, w_{o}^{*}, \theta_{x}^{*}, \theta_{y}^{*}, \theta_{z}^{*}$ and $\theta_{z}$ are the higher-order terms in the Taylor's series expansion and they represent higher-order transverse cross sectional deformation modes. Theoretical formulations and analytical solutions are developed for the static and dynamic analyses of antisymmetric angle-ply laminated composite and sandwich plates using all the above mentioned theories.

\section{NUMERICAL EXAMPLES AND DISCUSSIONS}

In this section, the numerical examples solved are presented and discussed to verify the accuracy of the higherorder shear deformation theories and first-order theory to bring out their response predictive capabilities. Governing equilibrium equations for stress analysis and equations of motion for free vibration analysis using the different displacement models are obtained using Principle of Minimum Potential Energy. For the stress analysis sinusoidal transverse loading is considered. The equations of motion for free vibration analysis are obtained using Hamilton's Principle. The closed form solutions are obtained using Navier's double trigonometric series technique for stress and free vibration analyses. Numerical results are presented for transverse displacement, in-plane stresses and natural frequencies using different models for anti-symmetric angle-ply laminated composite and sandwich plates. The accuracy of the solution is ascertained by comparing it with various available results in the literature.

\section{A. Static Analysis}

Example 1. A simply supported square laminate subjected sinusoidal transverse loading is considered. Laminate layers are of equal thickness. The normalized numerical values of maximum transverse deflection $\bar{w}$ in a two and four layered antisymmetric angle-ply $\left(45^{\circ} /-45^{\circ} / \ldots\right)$ square composite plates are given in Table I. The following plate material properties were taken from Ren [29] in obtaining numerical results.

$$
\text { Material 1 [29] } \begin{aligned}
E_{1} & =40 \times 10^{6} \mathrm{psi}(276 \mathrm{GPa}) \\
E_{2} & =E_{3}=1 \times 10^{6} \mathrm{psi}(6.895 \mathrm{Gpa}) \\
G_{12} & =G_{13}=0.5 \times 10^{6} \mathrm{psi}(3.45 \mathrm{GPa}) \\
G_{23} & =0.6 \times 10^{6} \mathrm{psi}(4.12 \mathrm{GPa}) \\
v_{12} & =v_{23}=v_{13}=0.25
\end{aligned}
$$

The results obtained from the present formulations using five models are compared with the analytical solution already published in the literature by Ren [29]. In case of thick laminates ( $a / h$ ratio 4 and 10$)$ with different fibre orientations considered, the values of normalized maximum transverse deflection predicted by Model-2 is very much closer to the values reported by Ren [29]. All other models show large difference in deflection values. For fibre orientation equal to $45^{\circ}$ and $a / h$ ratio equal to 4 , the maximum transverse deflection $\bar{w}$ values predicted by Model-1, Model-2, Model-3, Model-4 and Model-5 are 11.18\%, 8.96\%, 29.49\%, 29.49\%, and $20.01 \%$ lower for a two layered $(n=2)$ square composite plate and $5.26 \%, 3.41 \%, 13.91 \%, 13.91 \%$ and $14.22 \%$ lower for a four layered $(n=4)$ square composite plate as compared to the values obtained by Ren [29]. For thin laminates $(a / h=100)$, all the models give almost the same results and they are in very good agreement with those given by Ren [29]. 
TABLE I

NORMALIZED TRANSVERSE DEFLECTION IN A SIMPLY SUPPORTED ANTI-SYMMETRIC ANGLE- PLY $\left(45^{\circ} /-45^{\circ} \ldots\right)$ SQUARE LAMINATE UNDER SINUSOIDAL TRANSVERSE LOAD

\begin{tabular}{|c|c|c|c|c|}
\hline \multirow{2}{*}{$\theta$} & \multirow{2}{*}{$a / h$} & \multirow{2}{*}{ Models } & \multicolumn{2}{|c|}{$\overline{\overline{\bar{w}}}$} \\
\hline & & & $n=2$ & $n=4$ \\
\hline \multirow{18}{*}{$45^{\circ}$} & \multirow{6}{*}{4} & Ren [29] & 1.4471 & 1.0160 \\
\hline & & Model - 1 & 1.2852 & 0.9626 \\
\hline & & Model - 2 & 1.3175 & 0.9814 \\
\hline & & Model - 3 & 1.0203 & 0.8747 \\
\hline & & Model - 4 & 1.0203 & 0.8747 \\
\hline & & Model - 5 & 1.1576 & 0.8715 \\
\hline & \multirow{6}{*}{10} & Ren [29] & 0.6427 & 0.3201 \\
\hline & & Model - 1 & 0.6028 & 0.3101 \\
\hline & & Model - 2 & 0.6084 & 0.3114 \\
\hline & & Model - 3 & 0.5581 & 0.2956 \\
\hline & & Model - 4 & 0.5581 & 0.2956 \\
\hline & & Model - 5 & 0.5772 & 0.2912 \\
\hline & \multirow{6}{*}{100} & Ren [29] & 0.4685 & 0.1821 \\
\hline & & Model - 1 & 0.4649 & 0.1818 \\
\hline & & Model - 2 & 0.4682 & 0.1819 \\
\hline & & Model - 3 & 0.4676 & 0.1818 \\
\hline & & Model - 4 & 0.4676 & 0.1818 \\
\hline & & Model - 5 & 0.4678 & 0.1818 \\
\hline
\end{tabular}

Example 2. To study the flexural behaviour of laminated sandwich plate, a simply supported five layered square plate $\left(30^{\circ} /-30^{\circ} / \mathrm{core} / 30^{\circ} /-30^{\circ}\right)$ with isotropic core and antisymmetric angle ply face sheets is considered. The $a / h$ ratio considered equal to 4 . The following material properties [22] were used for laminated sandwich plates in obtaining numerical results.

Material 2 [22]

Face sheets ( Graphite Epoxy T300/934)

$E_{1}=19 \times 10^{6} \mathrm{psi}(131 \mathrm{GPa}) E_{2}=1.5 \times 10^{6} \mathrm{psi}(10.34 \mathrm{Gpa})$

$E_{2}=E_{3} \quad G_{12}=1 \times 10^{6} \mathrm{psi}(6.895 \mathrm{GPa})$

$G_{13}=0.90 \times 10^{6} \mathrm{psi}(6.205 \mathrm{GPa}) G_{23}=1 \times 10^{6} \mathrm{psi}(6.895 \mathrm{GPa})$

$v_{12}=0.22 \quad v_{13}=0.22 \quad v_{23}=0.49$

Core (Isotropic)

$E_{1}=E_{2}=E_{3}=2 G=1000 \mathrm{psi}\left(6.90 \times 10^{-3} \mathrm{GPa}\right)$

$G_{12}=G_{13}=G_{23}=500 \mathrm{psi}\left(3.45 \times 10^{-3} \mathrm{GPa}\right)$

$v_{12}=v_{13}=v_{23}=0$
The normalized maximum values of transverse deflection $\bar{w}$ and in-plane stresses $\bar{\sigma}_{x}, \bar{\sigma}_{y}$ and $\bar{\tau}_{x y}$ for different values of thickness of core to thickness of the face sheet $t_{c} / t_{f}$ ratio are given in Table II. For all the values of $t_{d} / t_{f}$ ratio the maximum transverse deflection and in-plane stress values obtained using Model-1 and Model-2 are in good agreement whereas considerable difference exists between these two and other models. In particular the first order theory (Model-5) very much underpredicts these values. For composite sandwich plates with $a / h$ ratio equal to 4 and $t_{c} t_{f}$ ratio equal to 10 , the normalized numerical values of transverse displacement $\bar{w}$ predicted by Model-2, Model-3, Model-4 and Model-5 are respectively $1.63 \%$ higher, $53.30 \%, 53.73 \%$ and $94.89 \%$ lower as compared to Model-1. Similar pattern in the percentage difference can be observed in the normalized numerical values of transverse displacement and in-plane stress values for all other ratios of $t_{d} t_{f}$.

TABLE II

NORMALIZED TRANSVERSE DEFLECTION AND IN-PLANE STRESSES IN A SIMPLY SUPPORTED FIVE LAYERED ANTISYMMETRIC ANGLE-PLY $\left(30^{\circ} /-30^{\circ} / \mathrm{CORE} / 30^{\circ} /-30^{\circ}\right)$ SQUARE SANDWICH PLATE UNDER SinUSOIDAL TRANSVERSE LOAD $(a / h=4)$

\begin{tabular}{cccccc}
\hline \hline \multirow{2}{*}{$t_{c} / t_{f}$} & Models & $\bar{w}$ & $\bar{\sigma}_{x}$ & $\bar{\sigma}_{y}$ & $\bar{\tau}_{x y}$ \\
\hline \multirow{3}{*}{4} & Model - 1 & 13.0335 & 1.0175 & 0.5013 & -0.5859 \\
& Model - 2 & 13.2429 & 1.0108 & 0.4982 & -0.5932 \\
& Model - 3 & 8.1972 & 0.5576 & 0.3002 & -0.3694 \\
& Model - 4 & 8.0144 & 0.6495 & 0.2744 & -0.3269 \\
& Model - 5 & 2.5977 & 0.2803 & 0.1510 & -0.1948 \\
\hline \multirow{3}{*}{10} & Model - 1 & 96.6657 & 3.4494 & 1.6989 & -1.8110 \\
& Model - 2 & 98.2424 & 3.2296 & 1.5387 & -1.8137 \\
& Model - 3 & 45.1407 & 1.4128 & 0.7554 & -0.9078 \\
& Model - 4 & 44.7308 & 1.6416 & 0.6980 & -0.8102 \\
& Model - 5 & 4.9418 & 0.4682 & 0.2591 & -0.3388 \\
\hline \multirow{2}{*}{20} & Model - 1 & 379.1888 & 7.1995 & 3.5922 & -3.6643 \\
& Model - 2 & 383.1255 & 6.5706 & 3.1104 & -3.6402 \\
& Model - 3 & 195.8631 & 3.3148 & 1.7080 & -2.0122 \\
& Model - 4 & 195.1197 & 3.7562 & 1.6034 & -1.8313 \\
\hline \hline
\end{tabular}




\section{B. Dynamic Analysis}

Example 3. The orthotropic material properties [30] of individual layers in all the square laminates considered are

$E_{1} / E_{2}=40, \quad E_{2}=E_{3}, \quad G_{23}=0.5 E_{2}$

$G_{12}=G_{13}=0.6 E_{2}, \quad v_{12}=v_{13}=v_{23}=0.25$

The comparison of normalized natural frequencies with respect to various side-to-thickness ratio $a / h$ for a two and eight layered square composite plate is presented in Table III and Table IV. The solution and results obtained using five models are compared with the values already published in the literature [30]. In the case two layered thick laminates ( $a / h$ ratios 2, 4, 5 and 10) the values predicted by Model-1 and Model-2 are very much closer whereas Model-3, Model-4 and Model-5 very much overpredicts these values.
For two layered composite plate with $a / h$ ratio equal to 5 , the normalized fundamental frequencies predicted by Model-2, Model-3, Model-4 and Model-5 are respectively $0.35 \%$ lower, $8.02 \%, 8.02 \%$ and $2.99 \%$ higher as compared to Model-1. For a eight layered composite plate with $a / h$ ratio equal to 5 , the normalized fundamental frequencies predicted by Model-2, Model-3, Model-4 and Model-5 are respectively $0.07 \%$ lower, $1.72 \%, 1.72 \%$ and $1.09 \%$ higher as compared to Model-1. This difference between the models tends to reduce for thin plates. Percentage difference in the numerical values obtained using above theories decreases significantly as the number of layers increases. Normalized fundamental frequency increases with increase in the number of layers.

TABLE III

NORMALIZED FundAMENTAL FREQUENCIES $\bar{\omega}=\left(\omega b^{2} / h\right) \sqrt{\rho / E_{2}}$ FOR A SiMPLY SUPPORTED Two LAYERED ANTISYMMETRIC ANGLE-Ply $\left(45^{\circ} /-45^{\circ}\right)$ SQUare LAMINATE.

\begin{tabular}{|c|c|c|c|c|c|}
\hline$a / h$ & Model-1 & Model-2 & Model-3 [30] & Model-4 [30] & Model-5 [30] \\
\hline 2 & 5.3325 & 5.3062 & 6.2837 & 6.3367 & 5.5205 \\
\hline 4 & 8.8426 & 8.8096 & 9.7593 & 9.7593 & 9.1681 \\
\hline 5 & 10.0350 & 9.9996 & 10.8401 & 10.8401 & 10.3352 \\
\hline 10 & 12.9115 & 12.8678 & 13.2630 & 13.2630 & 13.0439 \\
\hline 12.5 & 13.4690 & 13.4233 & 13.7040 & 13.7040 & 13.5500 \\
\hline 20 & 14.1705 & 14.1220 & 14.2463 & 14.2463 & 14.1790 \\
\hline 25 & 14.3500 & 14.3008 & 14.3827 & 14.3827 & 14.3385 \\
\hline 50 & 14.6012 & 14.5509 & 14.5723 & 14.5723 & 14.5608 \\
\hline 100 & 14.6668 & 14.6159 & 14.6214 & 14.6214 & 14.6182 \\
\hline \multicolumn{6}{|c|}{$\begin{array}{l}\text { NORMALIZED FUNDAMENTAL FREQUENCIES } \bar{\omega}=\left(\omega b^{2} / h\right) \sqrt{\rho / E_{2}} \text { FOR A SiMPLY SUPPORTED } \\
\text { EIGHT LAYERED ANTISYMMETRIC ANGLE-PLY }\left(45^{\circ} /-45^{\circ}\right)_{4} \text { SQUARE LAMINATE. }\end{array}$} \\
\hline$a / h$ & Model-1 & Model-2 & Model-3 [30] & Model-4 [30] & Model-5 [30] \\
\hline 2 & 5.9234 & 5.9227 & 6.2837 & 6.3140 & 5.8484 \\
\hline 4 & 10.7473 & 10.7401 & 10.9905 & 10.9905 & 10.8425 \\
\hline 5 & 12.7523 & 12.7429 & 12.9719 & 12.9719 & 12.8925 \\
\hline 10 & 19.1258 & 19.1150 & 19.2659 & 19.2659 & 19.2894 \\
\hline 12.5 & 20.7784 & 20.7688 & 20.8884 & 20.8884 & 20.9165 \\
\hline 20 & 23.1829 & 23.1764 & 23.2388 & 23.2388 & 23.2591 \\
\hline 25 & 23.8713 & 23.8659 & 23.9091 & 23.9091 & 23.9241 \\
\hline 50 & 24.8959 & 24.8925 & 24.9046 & 24.9046 & 24.9093 \\
\hline 100 & 25.1741 & 25.1714 & 25.1744 & 25.1744 & 25.1759 \\
\hline
\end{tabular}

Example 4. The comparison of normalized natural frequencies with respect to side-to-thickness ratio $a / h$ for different thickness of the core to thickness of the flange $t_{d} / t_{f}$ ratios, in a simply supported five layered square composite sandwich plate $\left(45^{\circ} /-45^{\circ} /\right.$ core $\left./ 45^{\circ} /-45^{\circ}\right)$ with isotropic core and antisymmetric angle-ply face sheets are given in Tables V. Material properties 2 [22] were used in obtaining numerical results. For $a / h$ ratio equal to 4 and $t_{d} / t_{f}$ ratio equal to 4 , the normalized frequency values predicted by Model-2, Model-3, Model-4 and Model-5 are $0.76 \%$ lower, 26.85\%, 26.85\% and $127.60 \%$ higher as compared to the values obtained by Model-1. As laminate becomes thin the difference between the result decreases. For all the values of $a / h$ ratios and $t_{d} / t_{f}$ ratio considered the numerical values obtained using Model-1 and Model-2 are in close agreement whereas considerable difference exists between these two and other models also the percentage difference in values with respect to Model-1 in predicting the natural frequencies is lesser in case of Model-2 and more in case of Model-5. In particular Model-5 very much overpredicts these values for all $a / h$ ratios and $t_{d} / t_{f}$ ratios. The results clearly shows that for all $t_{c} / t_{f}$ and $a / h$ ratio considered, The normalized fundamental frequency decreases as $t_{c} / t_{f}$ ratio increases and fundamental frequency increases as side-tothickness ratio $a / h$ increases. 
TABLE V

NORMALIZED FundAMENTAL FREQUENCIES $\bar{\omega}=\left(\omega b^{2} / h\right) \sqrt{\rho / E_{2}}$ FOR A SiMPLY SUPPORTED

FIVE LAYERED ANTISYMMETRIC $\left(45^{\circ} /-45^{\circ} /\right.$ CORE $\left./ 45^{\circ} /-45^{\circ}\right)$ SQUARE SANDWICH Plate.

\begin{tabular}{|c|c|c|c|c|c|c|c|}
\hline \multirow{2}{*}{$t_{c} / t_{f}$} & \multirow{2}{*}{ Models } & \multicolumn{6}{|c|}{$a / h$} \\
\hline & & 2 & 4 & 10 & 20 & 50 & 100 \\
\hline \multirow{5}{*}{4} & Model - 1 & 2.6404 & 4.5712 & 9.8197 & 15.0371 & 19.1695 & 20.0845 \\
\hline & Model - 2 & 2.5882 & 4.5363 & 9.7973 & 15.0173 & 19.1513 & 20.0667 \\
\hline & Model - 3 & 3.0986 & 5.7985 & 12.0510 & 16.8312 & 19.6858 & 20.2163 \\
\hline & Model - 4 & 3.0986 & 5.7985 & 12.0510 & 16.8312 & 19.6858 & 20.2163 \\
\hline & Model - 5 & 5.8321 & 10.4042 & 16.8482 & 19.3022 & 20.2263 & 20.3573 \\
\hline \multirow{5}{*}{10} & Model - 1 & 1.2805 & 2.1911 & 5.0653 & 9.2740 & 16.2062 & 19.3098 \\
\hline & Model - 2 & 1.2507 & 2.1737 & 5.0566 & 9.2675 & 16.1965 & 19.2970 \\
\hline & Model - 3 & 1.6929 & 3.2171 & 7.4895 & 12.6964 & 18.4604 & 20.1355 \\
\hline & Model - 4 & 1.6929 & 3.2171 & 7.4895 & 12.6964 & 18.4604 & 20.1355 \\
\hline & Model - 5 & 5.4606 & 9.9011 & 16.6538 & 19.4671 & 20.5661 & 20.7477 \\
\hline \multirow{5}{*}{20} & Model - 1 & 0.7538 & 1.3487 & 3.2154 & 6.1552 & 12.4654 & 16.7293 \\
\hline & Model - 2 & 0.7409 & 1.3414 & 3.2121 & 6.1527 & 12.4606 & 16.7182 \\
\hline & Model - 3 & 0.9806 & 1.8783 & 4.5392 & 8.4083 & 14.9592 & 18.0073 \\
\hline & Model - 4 & 0.9806 & 1.8783 & 4.5392 & 8.4083 & 14.9592 & 18.0073 \\
\hline & Model - 5 & 4.9451 & 9.0262 & 15.4250 & 18.1904 & 19.2936 & 19.4682 \\
\hline \multirow{5}{*}{50} & Model - 1 & 0.6079 & 1.1836 & 2.8972 & 5.5279 & 10.8499 & 14.1053 \\
\hline & Model - 2 & 0.6061 & 1.1825 & 2.8965 & 5.5248 & 10.8455 & 14.0969 \\
\hline & Model - 3 & 0.6473 & 1.2696 & 3.1080 & 5.8904 & 11.2731 & 14.3233 \\
\hline & Model - 4 & 0.6473 & 1.2696 & 3.1080 & 5.8904 & 11.2731 & 14.3233 \\
\hline & Model - 5 & 3.9813 & 7.2971 & 12.5940 & 14.9247 & 15.8633 & 16.0134 \\
\hline
\end{tabular}

\section{CONCLUSION}

In the present investigation, analytical formulation and solutions based on higher-order and first-order displacement fields have been applied to the static and dynamic analyses of simply supported antisymmetric angle-ply laminated composite and sandwich plates. Comparative study on the static and dynamic response of various shear deformation theories applied to multilayer composite and sandwich plates is presented. Exact solutions already available in the literature are used for comparison. The results of all the models compared include the transverse displacement, in-plane stresses and natural frequencies. The numerical results obtained by Model-1 and Model- 2 are in good agreement with the exact solution and other higher order theories. It brings out the fact that both transverse shear and normal deformations has to be taken in to account in the analysis of thick plates which undergoes cross sectional warping. The increasing importance of composite materials required refined theories for sandwich and laminate plates.

\section{REFERENCES}

[1] E. Reissner, and Y. Stavsky, "Bending and stretching of certain types of heterogeneous aelotropic elastic plates," ASME J. of Appl. Mech., vol. 28, pp. 402-408, 1961.

http://dx.doi.org/10.1115/1.3641719

[2] E. Reissner, "The effect of transverse shear deformation on the bending of elastic plates," ASME J. of Appl. Mech., vol. 12, no. 2, pp. 69-77,
1945.

[3] R. D. Mindlin, "Influence of rotary inertia and shear on flexural motions on isotropic, elastic plates," ASME J. of Appl. Mech., vol. 18, pp. 31-38, 1951.

[4] J. N. Reddy, "Mechanics of Laminated Composite Plates - Theory and Applications", CRC Press, 1997.

[5] N. J. Pagano, and S. J. Hatfield, "Elastic behavior of multilayered bidirectional composites", AIAA J., vol. 10, pp. 931-933, 1972. http://dx.doi.org/10.2514/3.50249

[6] Mallikarjuna and T. Kant, "A critical review and some results of recently developed refined theories of fiber-reinforced laminated composites and sandwiches", Compos. Struct., vol. 23, pp. 293-312, 1993.

http://dx.doi.org/10.1016/0263-8223(93)90230-N

[7] H. G. Allen, "Analysis and design of structural sandwich panels", Oxford, U. K: Pergamon Press; 1969.

[8] F. J. Plantema, "Sandwich construction, the bending and buckling of sandwich beams, plates and shells", New York: John Wiley; 1966.

[9] L. M. Habib, "A review of recent Russian work on sandwich construction", Int. J. of Mech. Sci., vol. 6(6), pp. 483-487, 1964. http://dx.doi.org/10.1016/S0020-7403(64)80010-2

[10] L. M. Habib, "A survey of modern developments in the analysis of sandwich structures", Appl. Mech. Rev., vol. 18(2), pp. 93-98, 1965.

[11] C. W. Bert, and P. H. Francis, "Composite material mechanics: Structural mechanics”, AIAA J., vol. 12(9), pp. 1173-1186, 1974. http://dx.doi.org/10.2514/3.49450

[12] K. Noor, and W. S. Burton, "Assessment of shear deformation theories for multilayered composite plates," Appl. Mech. Rev., vol. 42, no. 1, pp. $1-13,1989$. http://dx.doi.org/10.1115/1.3152418

[13] K. Noor, and W. S. Burton, "Assessment of computational model for multilayered composite shells," Appl. Mech. Rev., vol. 43, no. 4, pp. 6797, 1990.

http://dx.doi.org/10.1115/1.3119162 
[14] T. Kant, and K. Swaminathan, "Estimation of transverse/interlaminar stresses in laminated composites - A selective review and survey of current developments," Compos. Struct., vol. 49, no. 1, pp. 65-75, 2001. http://dx.doi.org/10.1016/S0263-8223(99)00126-9

[15] T. Kant, "Numerical analysis of thick plates," Comput. Methods in Appl. Mech. and Eng., vol. 31, pp. 1-18, 1982.

http://dx.doi.org/10.1016/0045-7825(82)90043-3

[16] N. Pandya, and T. Kant, "A consistent refined theory for flexure of a symmetric laminate," Mech. Res. Commun., vol. 14, pp. 107-113, 1987. http://dx.doi.org/10.1016/0093-6413(87)90026-7

[17] B. N. Pandya, and T. Kant, "A refined higher order generally orthotropic $\mathrm{C}^{\mathrm{o}}$ plate bending element," Comput. and Struct., vol. 28, pp. 119-133, 1988. http://dx.doi.org/10.1016/0045-7949(88)90031-4

[18] B. N. Pandya, and T. Kant, "Finite element stress analysis of laminated composites using higher order displacement model," Compos. Sci. and Technol., vol. 32, pp. 137-155, 1988 http://dx.doi.org/10.1016/0266-3538(88)90003-6

[19] T. Kant, and B. S. Manjunatha, "An unsymmetric FRC laminate $C^{\circ}$ finite element model with 12 degrees of freedom per node," Eng. Comput., vol. 5, no. 3, pp. 300-308, 1988. http://dx.doi.org/10.1108/eb023749

[20] T. Kant, and K. Swaminathan, "Free vibration of isotropic, orthotropic and multilayer plates based on higher order refined theories," J. of Sound and Vib., vol. 241, no. 2, pp. 319-327, 2001. http://dx.doi.org/10.1006/jsvi.2000.3232

[21] T. Kant, and K. Swaminathan, "Analytical solutions for free vibration of laminated composite and sandwich plates based on a higher order refined theory," Compos. Struct., vol. 53, no. 1, pp. 73-85, 2001. http://dx.doi.org/10.1016/S0263-8223(00)00180-X

[22] T. Kant, and K. Swaminathan, "Analytical solutions for static analysis of laminated composite and sandwich plates based on a higher order refined theory," Compos. Struct., vol. 56, no. 4, pp. 329-344, 2002. http://dx.doi.org/10.1016/S0263-8223(02)00017-X

[23] K. Swaminathan, and S. S. Patil "Higher order refined computational model with 12 degrees of freedom for the stress analysis of antisymmetric angle ply plates - analytical solutions," Compos. Struct., vol. 80, no. 4, pp. 595-608, 2007. http://dx.doi.org/10.1016/j.compstruct.2006.07.006

[24] K. Swaminathan, and S. S. Patil "Analytical solutions using a higher order refined computational model with 12 degrees of freedom for the free vibration analysis of antisymmetric angle ply plates," Compos. Struct., vol. 82, no. 2, pp. 209-216, 2008. http://dx.doi.org/10.1016/j.compstruct.2007.01.001

[25] K. Swaminathan, and S. S. Patil "Higher order refined computational models for the free vibration analysis of antisymmetric angle ply plates," J. of Reinf. Plast. and Compos., vol. 27, no. 5, pp. 541-553, 2008.

http://dx.doi.org/10.1177/0731684407084125

[26] J. N. Reddy, "A simple higher order theory for laminated composite plates," ASME J. of Appl. Mech., vol. 51, pp. 745-752, 1984. http://dx.doi.org/10.1115/1.3167719

[27] N. R. Senthilnathan, K. H. Lim, K. H. Lee, and S. T. Chow, "Buckling of shear deformable plates," AIAA J., vol. 25, no. 4, pp. 1268-1271, 1987. http://dx.doi.org/10.2514/3.48742

[28] J. M. Whitney, and N. J. Pagano, "Shear deformation in heterogeneous anisotropic plates," ASME J. of Appl. Mech., vol. 37, no. 4, pp. 10311036, 1970. http://dx.doi.org/10.1115/1.3408654

[29] J. G. Ren, "Bending, vibration and buckling of laminated plates, In: Cheremisinoff $N P$ " Handbook of Ceramics and Composites, New York: Marcel Dekkar: vol. 1, pp. 413-450, 1990.

[30] J. N. Reddy, and N. D. Phan, "Stability and vibration of isotropic, orthotropic and laminated plates according to higher order shear deformation theory," J. of Sound and Vib., vol. 98, no. 2, pp. 157-170, 1985 .

http://dx.doi.org/10.1016/0022-460X(85)90383-9

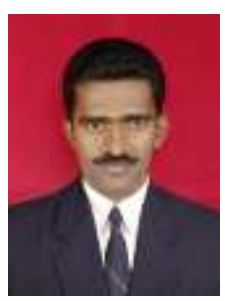

Dr. S. Shantharama Patil ; Born in Manipal, Karnataka, India on $15^{\text {th }}$ February 1971. He completed bachelor degree in Civil Engineering in 1997 from Manipal Institute of Technology, Manipal, under Mangalore University. He obtained Master's degree in Structural Engineering from Manipal Institute of Technology, Manipal, under Mangalore University in 1999. He joined as Lecturer in the Department of Civil Engineering, NITK, Surathkal on September 1999. After four year of experience, he joined in $\mathrm{PhD}$ program in Civil Engineering Department at NITK, Surathkal in 2003 and he obtained $\mathrm{PhD}$ degree in Civil Engineering from NITK, Surathkal in 2008. He joined as Associate Professor in the Faculty of Architecture, MIT, Manipal on February 2008 and from March 2013 he is working as Professor. He is having more than 15 years of teaching, research and consultancy experiences and taught at both undergraduate and postgraduate levels. He presented and published more than 50 research papers in National and International Conferences and International Journals. He organized workshops, conferences and short-term courses. He had been awarded National Doctoral Fellowship from AICTE/MHRD during his Doctoral studies. He is a reviewer of many International Journals. 